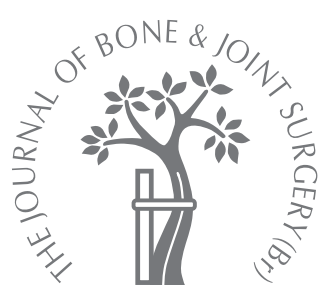

D. J. Culliford, J. Maskell, D. J. Beard, D. W. Murray, A. J. Price, N. K. Arden

From Southampton General Hospital, Southampton, England

D. J. Culliford, MSc, Medical Statistician

Research Design Service J. Maskell, MSc, Data Manager

Public Health Sciences and Medical Statistics

N. K. Arden, MD, FRCP, Professor of Rheumatic

Diseases

University of Southampton, Southampton General Hospital, Southampton SO16 6YD, UK.

D. J. Beard, MSc, DPhil, MCSP, Lecturer and Joint Head Oxford Orthopaedic Engineering Centre (Clinical) D. W. Murray, BChir, FRCS(Ortho), MD, Professor of Orthopaedic Surgery

A. J. Price, DPhil, FRCS, Reader in Musculoskeletal Sciences

Nuffield Orthopaedic Centre University of Oxford, Windmill Road, Oxford OX3 7LD, UK.

Correspondence should be sent to Professor N. K. Arden; e-mail: nka@mrc.soton.ac.uk

(C)2010 British Editorial Society of Bone and Joint Surgery doi:10.1302/0301-620X.92B1. $22654 \$ 2.00$

$J$ Bone Joint Surg $[\mathrm{Br}]$ 2010;92-B:130-5.

Received 30 March 2009;

Accepted after revision 22 July 2009

\title{
Temporal trends in hip and knee replacement in the United Kingdom
}

\author{
1991 TO 2006
}

\begin{abstract}
Using the General Practice Research Database, we examined the temporal changes in the rates of primary total hip (THR) and total knee (TKR) replacement, the age at operation and the female-to-male ratio between 1991 and 2006 in the United Kingdom.

We identified 27113 patients with THR and 23843 with TKR. The rate of performance of THR and TKR had increased significantly ( $p<0.0001$ for both) during the 16-year period and was greater for TKR, especially in the last five years. The mean age at operation was greater for women than for men and had remained stable throughout the period of study. The female-to-male ratio was higher for THR and TKR and had remained stable.

The data support the notion that the rate of joint replacement is increasing in the United Kingdom with the rate of TKR rising at the highest rate. The perception that the mean age for TKR has decreased over time is not supported.
\end{abstract}

The increasing size of the elderly population will raise the demand on healthcare systems. ${ }^{1}$ In order to monitor the increase and any subsequent attempt to manage the rising demand, accurate and up-to-date information is essential. While some estimates can be made, the impact of specific diseases requires more detailed attention since no useful general model can be applied. One such specific area in musculoskeletal medicine is the treatment of osteoarthritis (OA) by joint replacement.

OA of the hip and knee has a high prevalence in the population aged over 60 years ${ }^{2-5}$ and replacement surgery in both joints is considered to be successful and cost-effective for end-stage disease. Changing indications for joint replacement surgery, along with the increasing prevalence of $\mathrm{OA}$, particularly in younger patients, ${ }^{6,7}$ has meant that, historically, demand has usually outstripped supply. Recent waiting-list initiatives and other efforts to increase provision have partly reduced the immediate threat of unacceptably long waits for joint replacement. However, there is evidence from projection studies from the United States that the demand for total knee replacement (TKR) will double by 2015 and grow by $673 \%$ to nearly 3.5 million per annum by $2030 .{ }^{8}$ For the hip, the demand is expected to grow by $174 \%$ to 572000 joints per annum. It is notable that the requirement for TKR is set to be greater than for hips.
Data from the United States, although helpful, are not directly applicable to the United Kingdom and have other limitations. They are often incongruent with epidemiological findings from the United Kingdom. Many studies from the Western world have used data which terminated in the year 2000. There are few data from our National Health Service (NHS) with a corresponding lack of reports on temporal trends of total hip replacement (THR) and TKR, except for the study by Dixon et al. ${ }^{9}$

With limited funding for health-care, it is essential to track patterns of disease in order to target resources and validate common perceptions about changes in practice. One is that since OA of the knees is considered to be more prevalent and is diagnosed more readily, TKR is being performed at an increasingly younger age. The study by $\mathrm{Kim}^{1}$ substantiates this trend, as does the 2008 Annual Report from the Swedish Knee Arthroplasty Register. ${ }^{10}$ If this trend is shown to be universal, new treatment algorithms will be required to manage the local provision of replacement. The ratios of incidence by gender are unclear. It has been suggested that women have more THRs than men and vice versa for TKR. ${ }^{11,12}$ It is necessary to clarify this, along with the most likely age at which different subgroups undergo replacement.

With this background, our aim was to describe the rates, age at operation and gender ratios of THR and TKR in the United 
Table I. Details of general practice research database patients undergoing primary total hip or total knee replacement between 1991 and 2006

\begin{tabular}{|c|c|c|c|c|}
\hline & \multicolumn{2}{|l|}{ Hip } & \multicolumn{2}{|l|}{ Knee } \\
\hline & Women & Men & Women & Men \\
\hline Mean age in years at replacement (range) & 70.4 (18 to 103$)$ & $67.5(19$ to 100$)$ & 70.9 (18 to 99$)$ & 69.4 (19 to 98$)$ \\
\hline Number (\%) & $16969(62.6)$ & $10144(37.4)$ & $14121(59.2)$ & $9722(40.8)$ \\
\hline $\begin{array}{l}\text { Median (interquartile range) body mass index in } \mathrm{kg} / \mathrm{m}^{2} \\
\text { (most recent) }\end{array}$ & $26.3(23.3$ to 30.1$)$ & $27.1(24.6$ to 30.0$)$ & 28.5 (25.2 to 32.5$)$ & $27.9(25.4$ to 31.0$)$ \\
\hline Number & 14281 & 8658 & 12261 & 8488 \\
\hline Smokers (\%) & 11.4 & 14.4 & 8.1 & 12.3 \\
\hline Number & 16033 & 9616 & 13481 & 9344 \\
\hline
\end{tabular}

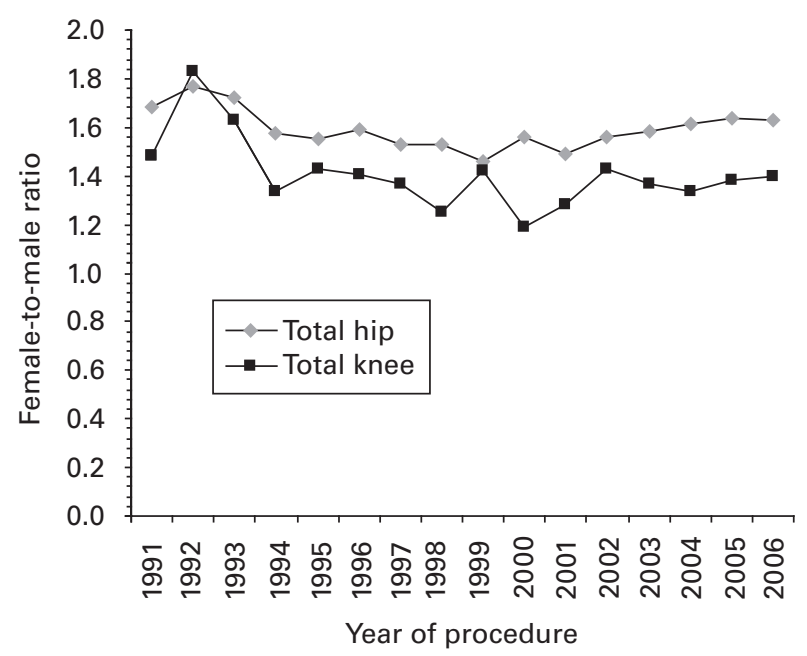

Fig. 1

Graph showing the gender ratio for the number of replacements against the year of procedure.

Kingdom and to answer questions on current issues, including the reported trend for surgeons to operate on younger patients.

\section{Patients and Methods}

We obtained data from the General Practice Research Database. This comprises the entire computerised medical records of a sample of patients attending general practitioners in the United Kingdom. It covers a population of 6.5 million patients from 433 contributing practices, chosen as being representative of the wider population in the United Kingdom. General Practitioners have a key role in providing primary care and referral to specialist services. Patients are registered with one practice which stores medical information from primary care and hospital attendances.

The database is administered by the Medicines and Healthcare Products Regulatory Agency. Its records contain all clinical and referral events in primary and secondary care along with comprehensive details of prescription data, clinical events, specialist referrals, hospital admissions and their major outcomes. The data are stored using Oxford Medical Information Systems (OXMIS) and Read codes for diseases which are cross-referenced to the International Classification of Diseases (ICD-9). ${ }^{13}$ OXMIS and Read coding systems are commonly used in general practice for the classification of all diseases. Only those practices which pass quality control are used in the General Practice Research Database. Deleting or encoding personal and clinic identifiers ensure confidentiality.

We identified all the patients in the database with a medical diagnosis code for THR or TKR between 1991 and the end of 2006. Read/OXMIS codes were used to identify primary THRs and TKRs. Patients were included if aged 18 years or over at operation. Those with a code for private practice were excluded as this variable has not been validated within the General Practice Research Database, therefore we could not be certain of its accuracy.

Statistical analysis. Age-gender standardised replacement rates for calendar years were calculated using ten-year age groups with the mid-year population estimates for 2003 as the reference standard. These estimates were published by the Office for National Statistics, ${ }^{14}$ the General Register Office for Scotland and the Northern Ireland Statistics and Research Agency. We computed the $95 \%$ confidence interval (CI) using a Poisson model appropriate for directly standardised rates.

The mean age at total replacement was calculated for the hip and knee for each calendar year and 95\% CIs computed. The age distribution at operation was calculated by gender for three consecutive five-year periods for the hip and knee, to investigate patterns over time.

\section{Results}

We identified 27113 primary THRs and 23843 primary TKRs between 1991 and 2006 (Table I). Women were 67\% more likely to undergo THR and $45 \%$ more likely to undergo TKR than men. They were on average almost three years older than men at THR, but this difference was halved for TKR. The female-to-male ratio (Fig. 1) for the estimated incidence rates has remained fairly stable from 1995 onwards, varying between 1.46:1 and 1.63:1 for hips 

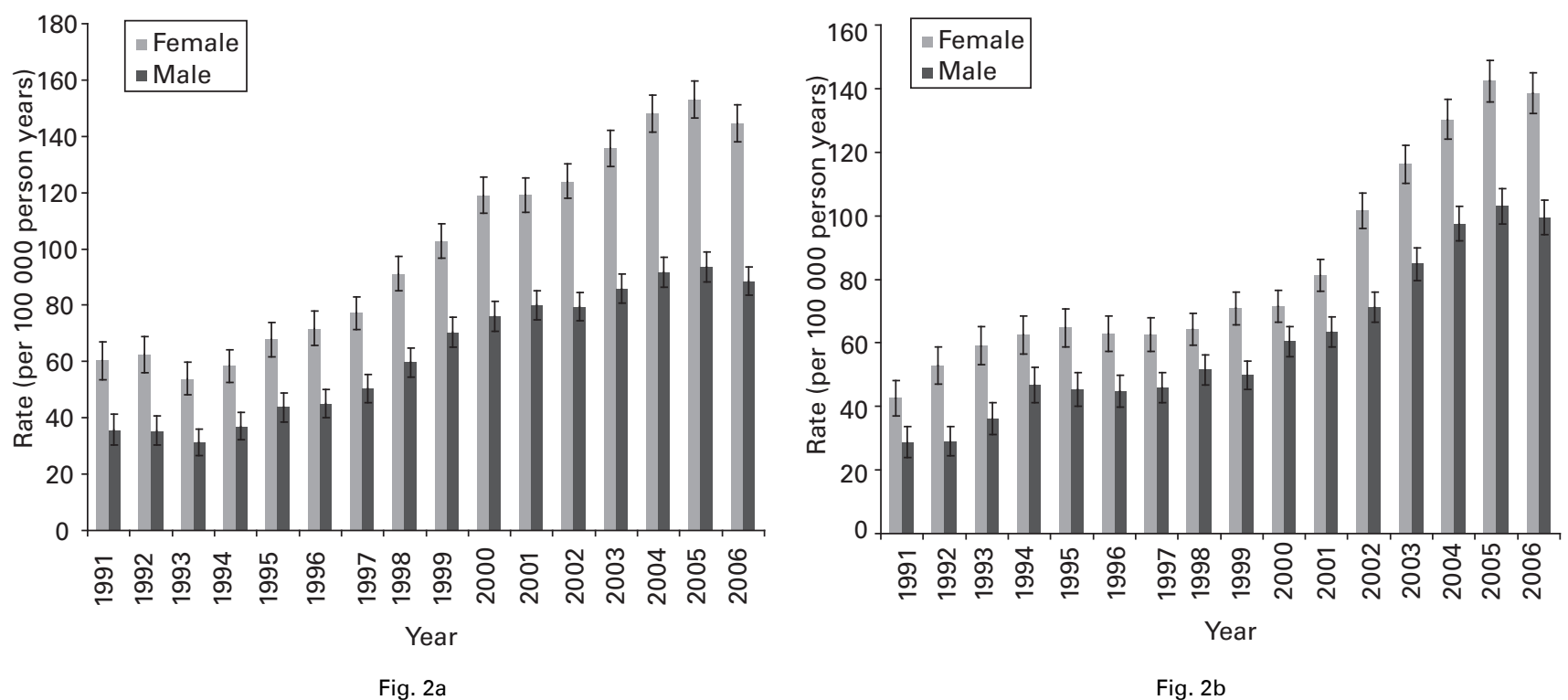

Fig. $2 b$

Bar charts showing the trends in replacement rates with the $95 \%$ confidence interval for 1991 to 2006 for a) total hip replacement and b) total knee replacement.

\begin{tabular}{|c|c|c|c|c|c|c|c|c|}
\hline \multirow[b]{3}{*}{ Age group (yrs) } & \multicolumn{4}{|l|}{ Hip } & \multicolumn{4}{|l|}{ Knee } \\
\hline & \multicolumn{2}{|l|}{ Women } & \multicolumn{2}{|l|}{ Men } & \multicolumn{2}{|l|}{ Women } & \multicolumn{2}{|l|}{ Men } \\
\hline & Number & Rate & Number & Rate & Number & Rate & Number & Rate \\
\hline 18 to 19 & 0 & 0.0 & 0 & 0.0 & 0 & 0.0 & 0 & 0.0 \\
\hline 20 to 29 & 3 & 1.5 & 2 & 1.0 & 2 & 1.0 & 3 & 1.6 \\
\hline 30 to 39 & 11 & 4.8 & 23 & 9.8 & 4 & 1.8 & 2 & 0.9 \\
\hline 40 to 49 & 45 & 19.0 & 48 & 19.5 & 37 & 15.7 & 33 & 13.4 \\
\hline 50 to 59 & 226 & 110.9 & 181 & 87.3 & 233 & 114.3 & 159 & 76.7 \\
\hline 60 to 69 & 566 & 230.1 & 368 & 226.0 & 551 & 331.1 & 452 & 277.6 \\
\hline 70 to 79 & 679 & 541.8 & 351 & 334.9 & 696 & 555.3 & 445 & 424.6 \\
\hline 80 to 89 & 352 & 441.4 & 156 & 330.8 & 293 & 367.4 & 182 & 385.9 \\
\hline 90 to 99 & 29 & 152.7 & 13 & 203.9 & 11 & 57.9 & 7 & 109.8 \\
\hline Total & 1911 & & 1142 & & 1827 & & 1283 & \\
\hline
\end{tabular}

and between 1.18:1 and 1.42:1 for knees. The body mass index of patients undergoing TKR was significantly greater than that for those with THR $(\mathrm{p}<0.0001)$ and this difference was greater for women than for men (Table I).

Hip replacement. Between 1991 and 2006, the estimated age-standardised rates for primary THR (100 000 person years) increased from 60.3 (95\% CI 53.7 to 67.0 ) to 144.6 (95\% CI 138.1 to 151.1 ) for women and from 35.8 (95\% CI 30.4 to 41.3 ) to 88.6 (95\% CI 83.4 to 93.7 ) for men. The rise in rates for hips was steady between 1993 and 2005 (Fig. 2a). When the 2006 rates for THR were applied to the mid-2006 population estimates for the United Kingdom, we obtained an estimated total number of primary THRs (excluding private practice) of 35437 (95\% CI 33847 to 37028 ) for women and 20346 (95\% CI 19165 to 21 527) for men.

Total knee replacement. During the period of study, the estimated age-standardised primary TKR rates increased from
42.5 (95\% CI 37.0 to 48.0 ) to 138.7 (95\% CI 132.3 to 145.0$)$ for women and from 28.7 (95\% CI 23.9 to 33.6) to 99.4 (95\% CI 93.9 to 104.8 ) for men. The temporal trend in rates for knees has not been as steady as that for hips, with a marked plateau from the mid-1990s, followed by a sharp rise from 2000. The estimated rates for women doubled between 2000 and 2006 (Fig. 2b). When the 2006 rates for TKR were applied to the mid-2006 population estimates for the United Kingdom, we obtained an estimated total number of primary TKRs (excluding private practice) of 33972 (95\% CI 32413 to 35 531) for women and 22 825 (95\% CI 21575 to 24075$)$ for men.

Age at operation. In 2006, the mean age at operation for THR was 70.3 years $(95 \%$ CI 69.8 to 70.8$)$ for women and 67.6 years $(95 \%$ CI 66.9 to 68.2$)$ for men. For TKR it was 70.1 years $(95 \%$ CI 69.6 to 70.5 ) for women and 69.2 years (95\% CI 68.6 to 69.7) for men. The highest rates of THR and 


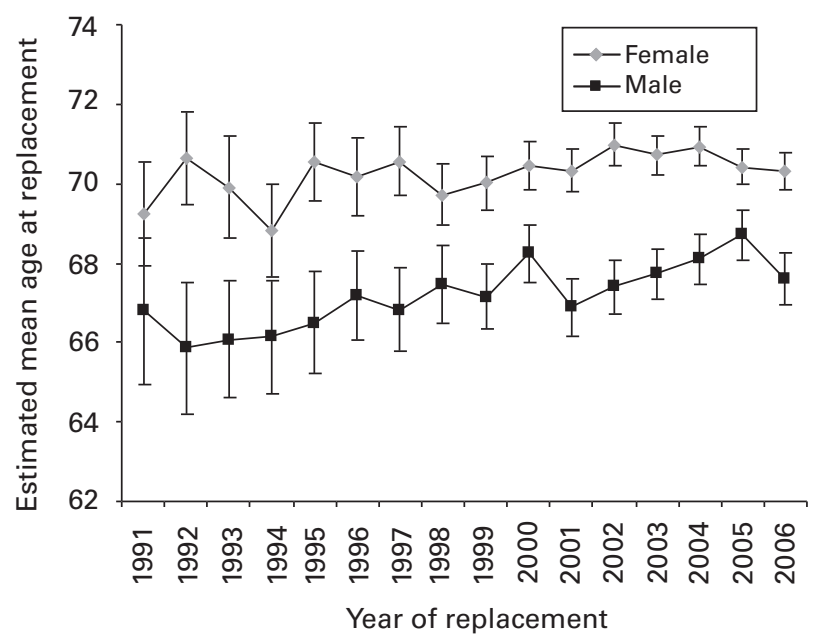

Fig. 3a

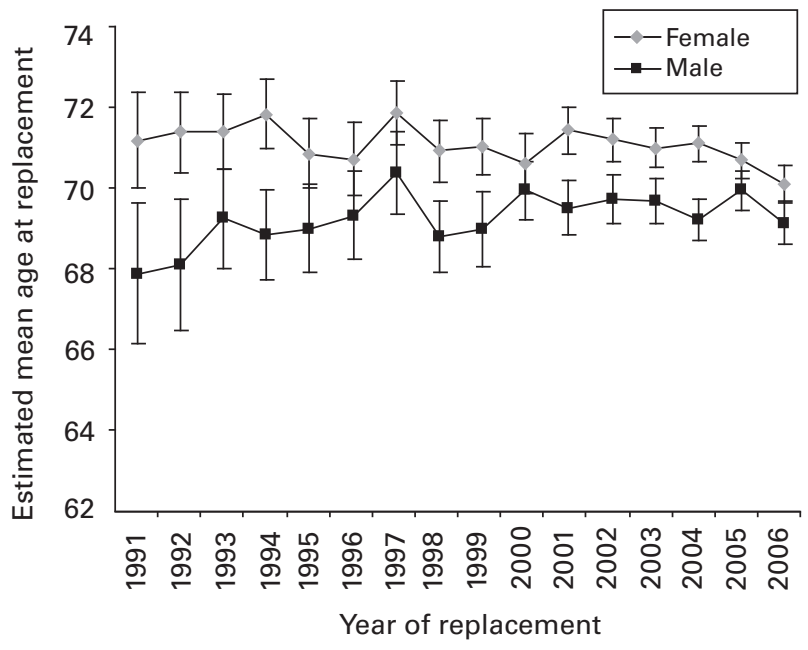

Fig. $3 b$

Graphs showing the mean age at replacement with the $95 \%$ confidence interval for 1991 to 2006 for a) total hip replacement and b) total knee replacement.

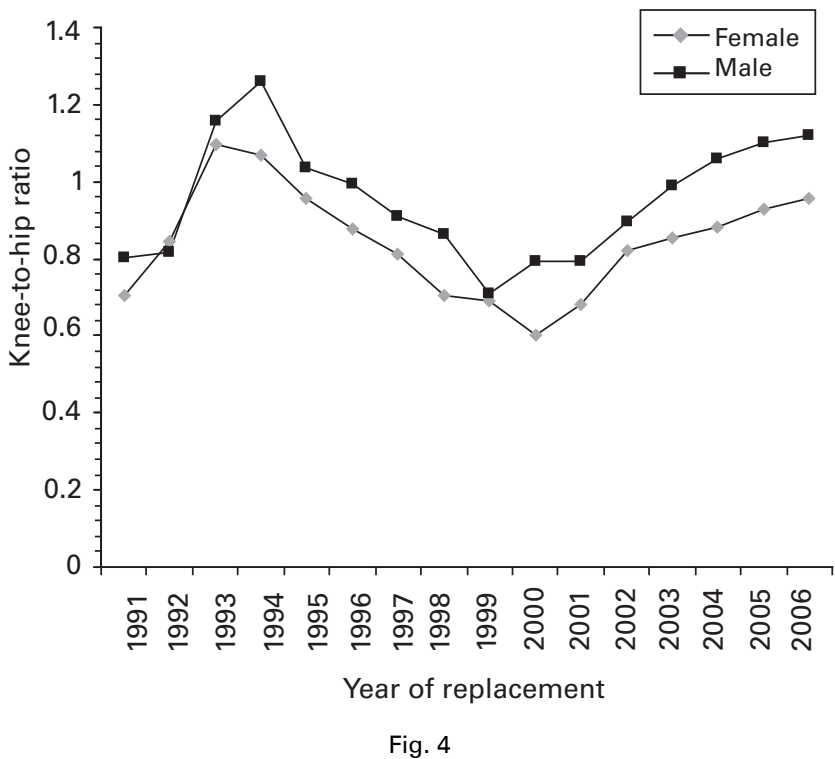

Graphs showing the ratio of incidence rates for total knee replacement versus total hip replacement for men and women between 1991 and 2006.

TKR were for women aged between 70 to 79 years (Table II). The mean rate for hips in this age group was 541.8 (95\% CI 501.0 to 582.5 ) and 555.3 (95\% CI 514.1 to 596.6 ) for knees. The number of replacements for those aged between 60 and 79 years comprised almost two-thirds of the total for hips $(64.3 \%)$ and a similar proportion for knees $(66.2 \%)$, with little gender difference in both cases.

The mean age at THR was significantly greater in women than in men for all years after 1991 (Fig. 3a). For TKR (Fig. 3b) the gender difference for the mean age at primary replacement was much narrower than that for hips, to the extent that it was not significantly greater in the last two years of the study. Although the mean age at TKR and THR in men appeared to have increased with time these changes did not reach statistical significance.

In order to explore the possibility that there had been a change in the distribution of the age of patients undergoing joint replacement surgery, we examined the distribution of age in five-year age bands over three periods: 1991 to 1995, 1996 to 2000 and 2001 to 2005 . The distribution of age across these time periods remained stable for both operations and genders.

The ratio of the incidence of TKR or THR was greater in men than in women (Fig. 4). It fell initially in both genders between 1994 and 2000, but has since been increasing in both to the extent that it is 1.1:1 for men and approaching parity for women.

\section{Discussion}

We have shown that the rate of primary THR has more than doubled and that for TKR more than trebled during the period of study. We have also demonstrated that the mean age at THR and TKR was similar and has remained stable during this period. The female-to-male ratio for replacement was greatest for THR and has also remained stable.

In order to validate the rates obtained from the General Practice Research Database, we calculated the number of primary total THRs (finished consultant episodes) from the Hospital Episode Statistics for 2005 to $2006 .{ }^{15}$ This contains data only for England and we therefore used mid-2006 population estimates to gross up to comparable figures for the United Kingdom. This method produced very similar estimates of 34905 THRs for women and 21008 for men and of 37548 TKRs for women and 26485 for men. This suggests that our data are as reliable as an estimate of joint replacement rates as the hospital episode statistics, but have the advantage of including 
Scotland, Wales and Northern Ireland. In order to validate our estimates further, we accessed data from the National Joint Registry, ${ }^{16}$ which covers England and Wales for NHS and private replacement operations. Although exact comparisons between sources were difficult, we extracted the number of hip and knee procedures at NHS hospitals and treatment centres in the financial year 2006 to 2007 as 51956 and 54604 respectively, after grossing-up to comparable figures for the United Kingdom using mid-2006 population estimates. These figures for THR and TKR, which included secondary procedures, were $6.9 \%$ and $3.9 \%$ less than the corresponding estimates from the General Practice Research Database. Given the various differences in the methods of data collection in these three sources along with the sampling variation within the General Practice Research Database, we are satisfied that our estimates represented the incidence of primary THR and TKR in the United Kingdom. It is accepted ${ }^{17,18}$ that patients included in the General Practice Research Database are broadly representative of the population of the United Kingdom with respect to age, gender, socio-economic class and region and further examples of this validation have been given by van Staa et al. ${ }^{19,20}$

We have shown that the increase in rates up to $2000^{9}$ has continued, but that it is more marked for TKR than THR. The reasons are likely to be multifactorial. It may be that the patterns reflect maturation in the development and acceptance for each type of implant. The older pedigree and surgical confidence with THR has been greater for longer. Conversely, TKR has a more recent documentation of reliability and has been the treatment of choice for a shorter period of time in strong contrast to the hip. A further and possibly more important reason, is the community burden of OA of the knee and hip. Radiological OA of the knee is approximately two to three times more prevalent than that of the hip in the general population. ${ }^{21}$ The number of TKRs per year is similar to that of THRs despite the much higher prevalence of $\mathrm{OA}$ of the knee. It is possible that the level of provision of THR is appropriate to the burden of OA of the hip whereas that for TKR is still below that required by surgeons operating on patients with lower levels of pain and disability.

One area of interest is the age of patients undergoing replacement and the perception that TKR is performed in younger patients. For the hip and knee, men are likely to undergo replacement earlier than women (Fig. 3). The reason is unclear, but may reflect the mean life expectancy of the genders.

The mean age for both operations remained stable between 1991 and 2006. By contrast to anecdotal belief, surgeons are not operating on younger patients with increasing frequency. This finding is supported by the consistent data on age distribution for primary TKR in the periods 1990 to 1995,1996 to 2000 and 2001 to 2005 . Our study also challenges the perception that surgeons now perform TKR on increasingly younger patients, since the mean age at TKR has not changed. The perception was probably created falsely by the increase in the number of young patients undergoing TKR as part of the general increase in the overall number of TKRs.

The gender distribution of replacement is noteworthy. THR and TKR in women have consistently outnumbered those of men and the pattern has changed little over the years. It is not clear whether this indicates that hip disease is more predominant in women than in men or whether it reflects a difference in the tolerance for surgical intervention for gender, either by patient or clinician.

The strengths of our study are that the dataset includes practices from the whole of the United Kingdom with a follow-up of up to 20 years. The dataset has been validated and audited and only the practices providing good quality data are admitted. A limitation of the General Practice Research Database is that it does not provide exact details of the indication for any procedure. However, provisional data suggest that the same trends are observed, as in the National Joint Registry in which around $90 \%$ to $95 \%$ of all THRs and TKRs are performed for OA.

Our study has shown that General Practice Research Database can provide useful data to describe trends in replacement practice in the United Kingdom. It confirms that the rate of replacement is increasing, with TKR showing the greater change. The perception that the mean age for TKR has decreased is not supported.

We gratefully acknowledge all the general practitioners and their patients who have consented to give information to the General Practitioner Research database. This study is based in part on data from the full feature General Practice Research Database obtained under licence from the UK Medicines and Healthcare Products Regulatory Agency. However, the interpretation and conclusions contained in this study are those of the authors alone. We also acknowlege the contribution of the members of the COAST study group (R. Azagra, A. Carr, N. Clarke, C. Cooper, K.Javaid, M. Mullee and J. Rafetery).

No benefits in any form have been received or will be received from a com mercial party related directly or indirectly to the subject of this article.

\section{References}

1. Kim S. Changes in surgical loads and economic burden of hip and knee replacements in the US: 1997 to 2004. Arthritis Rheum 2008;59:481-8.

2. Felson DT, Naimark A, Anderson J, et al. The prevalence of knee osteoarthritis in the elderly. Arthritis Rheum 1987;39:914-18.

3. Davies AP, Vince AS, Shepstone L, Donell ST, Glasgow MM. The radiologic prevalence of patellofemoral osteoarthritis. Clin Orthop 2002;402:206-12.

4. Dagenais S, Garbedian S, Wai EK. Systematic review of the prevalence of radiographic primary hip osteoarthritis. Clin Orthop 2009;467:623-37.

5. Quintana JM, Arostegui I, Escobar A, et al. Prevalence of knee and hip osteoarthritis and the appropriateness of joint replacement in an older population. Arch Intern Med 2008;168:1576-84

6. Ingvarsson T, Hagglund G, Lohmander LS. Prevalence of hip osteoarthritis in Iceland. Ann Rheum Dis 1999;58:201-7.

7. Grotle M, Hagen KB, Natvig B, Dahl FA, Kvien TK. Prevalence and burden of osteoarthritis: results from a population survey in Norway. J Rheumato/ 2008;35:67784

8. Kurtz S, Ong K, Lau E, Mowat F, Haplern M. Projections of primary and revision hip and knee arthroplasty in the United States from 2005 to 2030. J Bone Joint Surg [Am] 2007;89-A:780-5.

9. Dixon T, Shaw M, Ebrahim S, Dieppe P. Trends in hip and knee joint replacement socioeconomic inequalities and projections of need. Ann Rheum Dis 2004;63:825-30.

10. No authors listed. The Swedish Knee Arthroplasty Register: Annual Report 2008. http://www.knee.nko.se/english/online/uploadedFiles/112_SVK_2008Engl_1.1.pdf (date last accessed 30 November 2009). 
11. Srikanth VK, Fryer JL, Zhai G, et al. A meta-analysis of sex differences prevalence, incidence and severity of osteoarthritis. Osteoarthritis Cartilage 2005;13:769-81.

12. Kim HA, Koh SH, Lee B, et al. Low rate of total hip replacement as reflected by a low prevalence of hip osteoarthritis in South Korea. Osteoarthritis Cartilage 2008;16:1572-5.

13. World Health Organisation. International Classification of Diseases. http:// www.who.int/classifications/icd/en/ (date last accessed 25 September 2009).

14. No authors listed. Office for National Statistics. Key population and vital statistics series VS NO 30, PP1 No. 26, 2003. http://www.statistics.gov.uk/downloads/ theme_population/KPVS30_2003/KPVS2003.pdf (date last accessed 30 November 2009).

15. No authors listed. Hospital Episode Statistics. http://www.hesonline.nhs.uk (date last accessed 25 September 2008).
16. No authors listed. National Joint Registry for England and Wales. 5th Annual Report. ISSN1753-9374. http://www.njrcentre.org.uk (date last accessed 4 March 2009).

17. Parkinson J. Davis S, van Staa TP. The General Practice Research database: now and the future". In: Mann R, Andrews EB, eds. Pharmacovigilance, Secon ed. Chichester: John Wiley \& Sons Ltd, 2007:341-8.

18. Hollowell J. The general practice research database: quality of morbidity data. Population Trends 1997;87:36-40.

19. van Staa TP, Leufkens H, Abenhaim L, Zhang B, Cooper C. Use of oral corticosteroids and risk of fractures. J Bone Miner Res 2000;15:993-1000.

20. van Staa TP, Wegman S, de Vries F, Leufkens B, Cooper C. Use of statins and risk of fractures. JAMA 2001;285:1850-5.

21. Arden NK, Nevitt MC. Osteoarthritis: epidemiology. Best Pract Res Clin Rheumatol 2006;20:3-25. 